\title{
In vitro determination of the efficacy of scorpion venoms as anti-cancer agents against colorectal cancer cells: a nano-liposomal delivery approach
}

This article was published in the following Dove Press journal:

International Journal of Nanomedicine

13 January 2017

Number of times this article has been viewed

\author{
Abdulrahman $\mathrm{K} \mathrm{Al-Asmari}$ \\ Zabih Ullah' \\ Ali Al Balowi² \\ Mozaffarul Islam' \\ 'Department of Research, Prince \\ Sultan Military Medical City, Riyadh, \\ ${ }^{2}$ Department of Pharmacy, King \\ Fahad Armed Forces Hospital, \\ Jeddah, Saudi Arabia
}

Correspondence: Abdulrahman K Al-Asmari

Research Center, Prince Sultan, Military Medical City, PO Box 7897 (S-775),

Riyadh III59, Saudi Arabia

Tel +966 I 4791000 ext 25I00

Fax +966 | $47777 \mid 4$ ext 23060

Email abdulrahman.alasmari@gmail.com
Abstract: The use of liposomes in biological and medicinal sciences is a relatively new approach. The liposomal strategy greatly depends on the technological advancement in the formation of vesicles of various sizes and properties. In the current study, we encapsulated the venoms obtained from medically important scorpions such as Androctonus bicolor (AB), Androctonus crassicauda (AC), and Leiurus quinquestriatus (LQ). To begin with, our first and foremost aim was to prepare biocompatible and biodegradable nanovesicles. Additionally, we intended to enhance the anti-cancer potential of these encapsulated venoms. The liposomal venoms were prepared by rehydration and dehydration methods. Morphology, particle size, and size distribution of the liposomes were examined by scanning electron microscope (SEM), transmission electron microscope (TEM), and Zetasizer. We found that the prepared liposomes had a smooth surface and a spherical/ovoid shape and existed mainly as single unilamellar vesicles (SUVs). Furthermore, the liposomal formulation of all three venoms exhibited excellent stability and good encapsulation efficiency (EE). Additionally, the anti-cancer potential of the encapsulated venoms was also evaluated on a colorectal cancer cell line (HCT-8). The venomloaded liposomes showed elevated anti-cancer properties such as low rate of cell survival, higher reactive oxygen species (ROS) generation, and enhancement in the number of apoptotic cells. In addition to this, cell cycle analysis revealed G0/G1 enrichment upon venom treatment. The effect of treatment was more pronounced when venom-liposome was used as compared to free venom on the HCT-8 cell line. Furthermore, we did not observe any interference of liposomal lipids used in these preparations on the progression of cancer cells. Considering these findings, we can conclude that the encapsulated scorpion venoms exhibit better efficacy and act more vigorously as an anti-cancer agent on the colorectal cancer cell line when compared with their free counterpart.

Keywords: liposomes, scorpion venom, colon carcinoma cells, nanomedicine, anti-cancer

\section{Introduction}

Liposomes are tiny vesicles and are made up of the same macromolecules as those of the cell membrane. They can be formulated in a variety of sizes as unilamellar or multilamellar constructs. Liposomes are composed of naturally derived phospholipids with mixed lipid chains such as phosphatidylethanolamine (PDEA) and/or of pure surfactant components such as dioleoyl PDEA. In the natural form, the phospholipids are present in stable membranes composed of a bilayer. ${ }^{1}$ Liposome or lipid vesicles emerged from self-forming enclosed lipid bilayers upon hydration, which has played a leading role in the formulation of potent drugs to improve their therapeutic efficacy. ${ }^{2}$ Among the macromolecular systems that are useful for the targeted drug delivery, liposomes are 
extensively studied because they possess the most suitable features to be converted into multifunctional drug delivery options such as sustained and controlled release of the encapsulated material. ${ }^{3}$ Nano-formulations of medicinal drugs have attracted the interest of many researchers for drug delivery applications because these nano-formulations enhance the effectiveness of the conventional drug delivery system and are specific to the targeted delivery site. ${ }^{4} \mathrm{~A}$ few examples of the extensively used drug liposomes are antimicrobial and antineoplastic drugs, vaccines, chelating agents, steroids, and genetic materials. ${ }^{5}$ Furthermore, the flexible nature of the liposomes and their properties of altering the pharmacokinetics and pharmacodynamics have been preferred over the conventional therapeutic means to deliver the encapsulated drug efficiently. ${ }^{6}$

Conventional therapeutic agents have numerous shortcomings such as burst release, non-target therapy, and massive side effects. To eliminate these deficiencies, liposome technologies have emerged in modern biological research. This technology has made a remarkable achievement in the therapeutic field and in biotechnology for delivering the effective therapeutic agents to the site of action with minimal side effects. ${ }^{7}$ Inculcating the role of liposomal technology in the drug delivery system for the treatment of various chronic diseases, including cancer, is an innovative approach. To further improve the distribution of therapeutic drugs, some modified liposome carriers have been designed with optimal sizes and modified surface areas. ${ }^{8}$ These vesicular carriers are versatile in their nature. They can deliver the drug to the tumors much efficiently than the conventional methods. However, care should be taken to ensure that the modified vesicular carriers retain the following important properties: they should be durable in blood and specific to the tumor, react to internal/external stimuli, and promote intracellular drug delivery. ${ }^{9}$

Rendering the chemotherapy efficiently and safely to the patients has remained a significant challenge until recently. Additionally, cancer cells are more vulnerable than normal cells toward the effects of anti-cancer agents. Furthermore, most of these therapeutic measures/drugs are non-target specific. Consequently, the chances are high that they might harm/damage the surrounding body tissues if given unprotected. Therefore, liposomal drug delivery approach, which is much safer and target specific, is an accepted tool these days. ${ }^{10-13}$ Therefore, the nanomedicine approach has been well recognized in different areas of drug delivery for improving the effectiveness of biomolecules such as venoms and other toxins.

Purified toxins derived from whole venom and its active components are already in clinical use or under clinical trial. ${ }^{14-16}$ However, not much work has been done on the aspect of encapsulated scorpion venoms/toxins prior to their use on cancer patients. Therefore, in the near future, encapsulated products will be an additional helpful tool with a great therapeutic value in the field of cancer therapy. Additionally, from new antibiotics to potential anti-cancer constituents, scorpion venom has been found to hold an effective source of biologically active molecules. ${ }^{17}$ Many of these components have been found with the unique properties to circumvent the global therapeutic challenges. ${ }^{18}$ Venoms and purified toxins of scorpion, such as chlorotoxin (a 36-amino acid peptide), are effective inhibitors of glioma cells. A synthetic peptide from chlorotoxin (TM-601) has the capability to cross the blood-brain barrier, and it is also used in clinical trials for treating glioma. ${ }^{19}$ Stoppin, a toxin from the venom of the scorpion Buthus martensii, can kill tumor cells. ${ }^{20}$ Bengalin, a protein from the scorpion Heterometrus bengalensis, has selective cytotoxic potential for leukemic cells. ${ }^{21}$

Hence, the purpose of using the liposomal delivery approach in the current study was to establish and observe the fact of enhanced venom activity against the HCT- 8 cell line. Additionally, we also examined the adverse effect of lipid components of the liposome. Interestingly, we observed that the lipid moieties used in this study were non-toxic in nature and safe, and thus they can be used without any risk in future studies. Furthermore, both the lipid bilayers and the aqueous core of liposomes can serve as a reservoir for the drug or venom, which is easily degradable after delivering the active molecules to the target site. ${ }^{22-24}$

In conclusion, our results showed an enhanced and very effective role of encapsulated scorpion venom against the progression of the HCT-8 cell line. Therefore, in future, liposomal scorpion venom (toxin) therapy will be an effective approach to minimize the spread and metastasis of aggressive colorectal cancer cells. Additionally, considering the very promising role of scorpion venom, particularly in an encapsulated form against colorectal cancer, a detailed study of the purified form of the venom (toxin) using a xenograft mouse model is warranted in future.

\section{Materials and methods Collection of scorpion venom}

The collection of scorpion and isolation of venom was undertaken after the approval of research ethics committee (REC) of Prince Sultan Military Medical City (PSMMC) Hospital, Riyadh, Saudi Arabia. The REC is also responsible for animal care and ethics at PSMMC. The experiments were performed based on the guidelines set forth for the use of animals by the REC, as mentioned earlier. ${ }^{25}$ Medically important scorpions 
such as Androctonus bicolor (AB), Androctonus crassicauda (AC), and Leiurus quinquestriatus (LQ) were collected from different regions of the Kingdom of Saudi Arabia by an expert and designated person. The scorpions were fed with mealworms and water ad libitum. The venoms from the scorpions were milked by electrical stimulation using Harvard 6012 stimulator (Harvard Apparatus, Holliston, MA, USA). The ejected venoms were collected in glass vials and immediately stored at $-20^{\circ} \mathrm{C}$. The venoms were recovered by mixing them with distilled water followed by centrifugation at $10,000 \mathrm{rpm}$ for $10 \mathrm{~min}$ at $4^{\circ} \mathrm{C}$. The supernatants thus obtained were lyophilized and stored at $-80^{\circ} \mathrm{C}$ until used for the treatments. Stock venom concentration of $10 \mathrm{mg} / \mathrm{mL}$ was prepared in phosphate-buffered saline (PBS) and sterilized by passing through a $0.22-\mu \mathrm{m}$ membrane filter (Thomas Scientific, Swedesboro, NJ, USA) before use. Further dilutions were made in the same buffer system as required.

\section{Formulation of liposomes and encapsulation of venoms}

Dehydrated liposomes were formed from homogeneous dispersions of different ratios of phospholipid 1,2-distearoylsn-glycero-3-phosphocholine (DSPC) and cholesterol in a tert-butyl alcohol (TBA)/water co-solvent system. The isotropic monophasic solution of liposomes was freeze-dried to generate dehydrated liposomal powder in a sterile vial. This freeze-dried method left empty lipid vesicles after removing water and TBA from the vial. The venom was encapsulated by the dehydration-rehydration method. Next, the liposomes formed in the previous step were hydrated with the venom $A B$ in PBS at $37^{\circ} \mathrm{C}$. Furthermore, the whole mixture was incubated for $2 \mathrm{~h}$ at $37^{\circ} \mathrm{C}$. Mannitol $0.5 \%(\mathrm{w} / \mathrm{v})$, which acts as a cryopreservative, was added to the mixture before freezing in a liquid nitrogen bath. The frozen mixture was lyophilized at a temperature of $-40^{\circ} \mathrm{C}$ and a pressure of 5 mbar overnight. The lyophilized cake was resuspended in normal saline to obtain the desired concentration of venom. The unincorporated venom was removed from the entrapped one by spinning the preparation at $10,000 \mathrm{rpm}$ for $30 \mathrm{~min}$ at $4^{\circ} \mathrm{C}$. After washing the venom-liposome three times, the precipitates settled in the bottom were resuspended in normal saline before use. To achieve the optimal uniformity in the subsequent results, we standardized the process of encapsulation using venom $A B$. This venom-liposome preparation exhibited optimal results, as shown in Table 1. Therefore, this particular preparation was used as the model for the other two venoms, ie, AC and LQ, used in the subsequent studies.

\section{Determination of encapsulation efficiency}

Encapsulation efficiency (EE) of the liposome was determined by the centrifugation method. Disposable syringes $(1 \mathrm{~mL})$ were plugged with cotton and filled with hydrated Sephadex G-25M gel (1\%, m/v), which had previously been soaked in $0.9 \%(\mathrm{v} / \mathrm{v})$ saline for $1 \mathrm{~h}$. These syringes were placed in a plastic centrifuge tube, and the whole assembly was centrifuged at $8,000 \mathrm{rpm}$ for $15 \mathrm{~min}$ at $4^{\circ} \mathrm{C}$ to keep the bed dry. To this dried bed, $0.5 \mathrm{~mL}$ of liposomal suspension was added, and the assembly was again spun at 3,000 rpm for $15 \mathrm{~min}$ at $4^{\circ} \mathrm{C}$. This repeated centrifugation was needed to separate the free or unincorporated venom from the venom liposome. This process was repeated six times using new syringes packed with gel each time to ensure complete removal of the non-entrapped free venom (FV). At the completion of washing, quantitation of the venom was done by the Bradford dye binding method. ${ }^{26}$

The percentage of venom encapsulation was calculated using the following equation:

$$
\operatorname{EP}(\%)=\frac{C_{t}-C_{r}}{C_{t}} \times 100
$$

Table I EE and particle size of the venom AB-encapsulated liposomes with different ratios of phospholipid, cholesterol, and solvents

\begin{tabular}{|c|c|c|c|c|c|c|}
\hline Formulations & $\begin{array}{l}\text { DSPC } \\
(\mathrm{mg})\end{array}$ & $\begin{array}{l}\text { Cholesterol } \\
\text { (mg) }\end{array}$ & $\begin{array}{l}\text { tert-butyl } \\
\text { alcohol }(\mathrm{mL})\end{array}$ & $\begin{array}{l}\text { Water for } \\
\text { injection }(\mathrm{mL})\end{array}$ & $\begin{array}{l}\text { EE }(\%), \\
\text { mean } \pm \text { SD }\end{array}$ & $\begin{array}{l}\text { Liposomal size } \\
(\mathbf{n m}), \text { mean } \pm \text { SD }\end{array}$ \\
\hline$\overline{V L I}$ & 100 & 5 & 10 & 10 & $48.5 \pm 14.5$ & I,056.8土40.4 \\
\hline VL2 & 90 & 10 & 10 & 10 & $51.4 \pm 12.8$ & $882.6 \pm 52.3$ \\
\hline VL3 & 80 & 15 & 10 & 10 & $51.8 \pm 8.7$ & $738.7 \pm 42.5$ \\
\hline VL4 & 70 & 20 & 10 & 10 & $52.4 \pm 8.5$ & $652.6 \pm 32.5$ \\
\hline VL5 & 60 & 25 & 10 & 10 & $54.8 \pm 12.3$ & $419.5 \pm 31.5$ \\
\hline VL6 & 50 & 30 & 10 & 10 & $55.5 \pm 8.7$ & $235.8 \pm 12.5$ \\
\hline VL7 & 40 & 35 & 10 & 10 & $42.5 \pm 8.5$ & $198.4 \pm 25.4$ \\
\hline VL8 & 30 & 40 & 10 & 10 & $40.8 \pm 12.2$ & $150.6 \pm 22.5$ \\
\hline VL9 & 20 & 45 & 10 & 10 & $36.7 \pm 8.5$ & $169.4 \pm 18.4$ \\
\hline VLIO & 10 & 50 & 10 & 10 & $32.4 \pm 9.8$ & $|68.2 \pm 2| .4$ \\
\hline
\end{tabular}

Abbreviations: AB, Androctonus bicolor; DSPC, 1,2-distearoyl-sn-glycero-3-phosphocholine; EE, encapsulation efficiency; VL, venom-liposome. 
where EP is the encapsulation percentage, $\mathrm{C}_{t}$ the concentration of total toxin, and $\mathrm{C}_{\mathrm{r}}$ the concentration of free toxin.

\section{In vitro release of venoms from liposomal preparation}

The in vitro release of venoms from the liposomal formulation was determined by the dialysis sac method. Normal saline was used as a medium for in vitro release studies. The $\mathrm{pH}$ of the solution was maintained at 7.5. Approximately $0.5 \mathrm{~mL}$ of the liposomal suspension was placed in the dialysis sac (regenerated cellulose membrane of pore size $50 \mathrm{kDa}$, procured from Spectrum Labs, Karnataka, India), which was immersed in $100 \mathrm{~mL}$ of normal saline maintained at $37^{\circ} \mathrm{C}$ with constant stirring. A total of $1 \mathrm{~mL}$ of the normal saline was withdrawn at time intervals of $0,15,30,60,90,120,150$, 180, and $240 \mathrm{~min}$. For maintaining the sink conditions, an equal volume of normal saline was replenished. The samples were analyzed for the venom contents. This experiment was done in triplicate, and the average percentage obtained was calculated to find out the venom release.

\section{Morphological studies of the liposomes}

The following parameters were studied in the morphological evaluation.

\section{Scanning electron microscope}

The surface morphology of liposomes was studied using a scanning electron microscope (SEM; EVO LS10; Zeiss, Cambridge, UK). Samples were mounted on stubs using adhesive carbon tape (SPI Supplies, West Chester, USA) on both sides, which was coated with gold under vacuum in a Q150R sputter coater unit, procured from Quorum Technologies Ltd. (East Sussex, UK) in an argon atmosphere at $20 \mathrm{~mA}$ for $120 \mathrm{~s}$. After coating the liposomes, they were viewed and photographed to study the surface structure.

\section{Transmission electron microscope}

The morphology of liposomes containing venom was observed using a transmission electron microscope (TEM) apparatus (JEM-1230; JEOL, Tokyo, Japan). A drop of liposomal sample was placed on a carbon-coated copper grid, which was negatively stained with $2 \%$ phosphotungstic acid and then viewed under TEM and photographed. The detailed procedure of TEM was followed as reported earlier. ${ }^{27}$

\section{Particle size, polydispersity index, and zeta potential}

Particle size analysis, polydispersity index (PDI), and zeta potential of the prepared liposomes were determined using a Zetasizer (Nano ZS analyzer; Malvern Instruments, Malvern, UK). Briefly, $15 \mu \mathrm{L}$ of liposomes was diluted to 100 -fold with ultrapure water and mixed vigorously, before their measurement at $25^{\circ} \mathrm{C}$. The dynamic light scattering data for the liposomes were collected using a helium laser as a light source, and the mean results were obtained using photon correlation spectroscopy as described by Chen et al. ${ }^{27}$

\section{Stability studies}

Physical stability tests of the liposomes were performed to evaluate the effect of storage conditions. The prepared liposomes were stored in glass vials tightly packed with a cork lid at $4{ }^{\circ} \mathrm{C} \pm 1^{\circ} \mathrm{C}$ for 4 weeks and at $25^{\circ} \mathrm{C}$ for 3 months. For the entire study period, the stability of the liposomes was periodically evaluated by the measurement of their EE, particle size, physical appearance, aggregation, and sedimentation.

\section{In vitro anti-cancer studies}

\section{Cell culture}

HCT-8 cancer cell lines were procured from American Type Culture Collection (ATCC; Manassas, VA, USA). These cell lines were grown at $37^{\circ} \mathrm{C}$ in a humidified atmosphere with $95 \%$ air- $5 \% \mathrm{CO}_{2}$ as reported earlier. ${ }^{17}$

\section{Cell viability, oxidative stress, apoptosis, and cell cycle} arrest assays

All these four cellular parameters were examined on Muse Cell Analyzer (EMD Millipore, Billerica, MA, USA).

\section{Cell viability assay}

The cell viability assay was performed in 24-h pretreated HCT-8 cell lines using different concentrations of nanoliposomal venoms (AB, AC, and LQ). The assay was conducted as per the kit supplier's protocol. Briefly, $12 \times 10^{4}$ cells from control and toxin-treated cells were taken in $200 \mu \mathrm{L}$ of PBS and mixed with $380 \mu \mathrm{L}$ of cell counting solution (provided by the instrument's manufacturer, Cat No $\mathrm{MCH}$ 100102). Contents were mixed gently for a few seconds and immediately read on the machine using specific programming. A histogram showing numeric values gave the numbers of live and dead cells.

\section{Oxidative stress}

To determine the effect of liposomal venom (LV) on oxidative stress, the assay was performed using the kit provided by the manufacturer of Muse Cell Analyzer (Cat No MCH 100111-2) as reported earlier. ${ }^{25}$ Muse Oxidative Stress Kit allows for the quantitative measurements of reactive oxygen 
species (ROS), namely, superoxide radicals in cells undergoing oxidative stress. At the completion of the nanomodified venom treatment, which was done as described in the Cell viability assay section, cells were collected, centrifuged, and resuspended in $1 \mathrm{X}$ assay buffer at $1 \times 10^{6}-1 \times 10^{7}$ cells/ $\mathrm{mL}$. Cell suspensions were incubated with Muse Oxidative Stress working solution. The same reagent was diluted to 1:100 with $1 \mathrm{X}$ assay buffer to make an intermediate solution. Again, this intermediate solution was diluted to 1:80 with $1 \mathrm{X}$ assay buffer to make it the working solution. Finally, $190 \mathrm{~mL}$ of this solution was mixed with $10 \mu \mathrm{L}$ of the cell suspension and incubated at $37^{\circ} \mathrm{C}$ for $30 \mathrm{~min}$ prior to analysis.

\section{Apoptosis assay}

To evaluate the extent of early and late apoptosis caused by the nanomodified venoms, we used dead cell kit from EMD Millipore (Cat No MCH 100105). Using appropriate programming on the cell analyzer, the numbers of live, dead, early, and late apoptotic cells were determined. Total apoptosis was calculated by summing up the number of cells from late and early apoptotic quadrants of the histograms.

\section{Cell cycle assay}

In order to determine the effect of nanomodified venoms on cell cycle arrest, the kit provided by the manufacturer of Muse Cell Analyzer (Cat No MCH 100106) was used. At the completion of the nanomodified venom treatment, the cells were harvested and counted. Approximately $12 \times 10^{4}$ cells from control and treated groups were fixed in $75 \%$ ethyl alcohol for $3 \mathrm{~h}$ at $-20^{\circ} \mathrm{C}$. Furthermore, cells were washed once with PBS and incubated with $200 \mu \mathrm{L}$ of assay solution for $30 \mathrm{~min}$ at room temperature. After the completion of incubation time, the cells were vortexed gently and read on the cell analyzer. The number of cells at each point, namely, $\mathrm{G} 0 / \mathrm{G} 1, \mathrm{~S}$, and G2/M phases, was analyzed in control and nanomodified toxin-treated cells.

\section{Results}

\section{Formulation and optimization of nano- liposomal venom}

For the preparation of liposomes, phospholipid and cholesterol were chosen as the core components. These core constituents were also used in earlier reports. ${ }^{28}$ Different concentrations of phospholipid were incorporated with cholesterol in various batches of the formulation as depicted in Table 1. The amount of TBA and water was kept constant. The liposomes thus prepared by the dehydration and rehydration method were evaluated for their EE and vesicle size.
Furthermore, these combinations in preparation play a major role in venom encapsulation and therapeutic effectiveness. The formulation of the liposomal structure was confirmed by TEM and SEM. As given in Table 1, the ratio of lipid and cholesterol plays a significant role in determining the size and EE of the liposomes. The liposomal size from the combination of venom-liposome (VL)1 to VL10, decreases, whereas there is an increase in the EE up to the formula VL6, and afterward, it follows the downtrend of particle size. The formulation VL1 shows the largest size of the liposomes as the amount of lipid is highest in this case, and the formulation VL10 shows the smallest size and least EE as the amount of lipid is lowest in this formulation. The formulation VL6 was chosen as the optimal formulation, as this combination showed the highest EE and the optimal liposomal size. Therefore, this formula was considered as the model for further preparation of liposomes with the venoms.

\section{Determination of EE}

Results of venom encapsulation showed that the ratio of lipid versus cholesterol was the main factor affecting the EE of the liposomes. The encapsulated venoms were separated based on the size. This process was repeated six times using fresh syringes packed with fresh gel each time to ensure complete removal of the non-entrapped FV as stated in methodology. The mean EE of the developed formulation with venom $\mathrm{AB}$ was found to be $53.1 \% \pm 2.2 \%$, whereas the mean $\mathrm{EE}$ of liposomes with venoms AC and LQ was found to be $49.55 \% \pm 4.1 \%$ and $51.3 \% \pm 3.8 \%$, respectively.

\section{In vitro release of venoms from liposomal preparation}

The cumulative venom release in normal saline was determined using $0.5 \mathrm{~mL}$ (equivalent to $500 \mu \mathrm{g}$ of venom) of a liposomal formulation. The amount of venom released in normal saline was measured at various time intervals up to $4 \mathrm{~h}$. Release studies showed that there was a burst release of the venoms (AB, AC, and LQ) during the first $30 \mathrm{~min}$; after that, the rate of release was significantly reduced, but followed a constant increasing trend (Figure 1). After $150 \mathrm{~min}$, due to the equal venom concentration between the donor and the receptor compartments, the plateau phase was observed. The cumulative venom release data showed the release rates up to $4 \mathrm{~h}$ as $96.3 \% \pm 2.3 \%, 96.2 \% \pm 0.3 \%$, and $97.8 \% \pm 0.6 \%$ for venoms AB, AC, and LQ, respectively. Therefore, it can be concluded from these in vitro characterization tests that the liposomal formulations of the venoms were optimal and could be used to evaluate their efficiency on cancer cell line(s). 


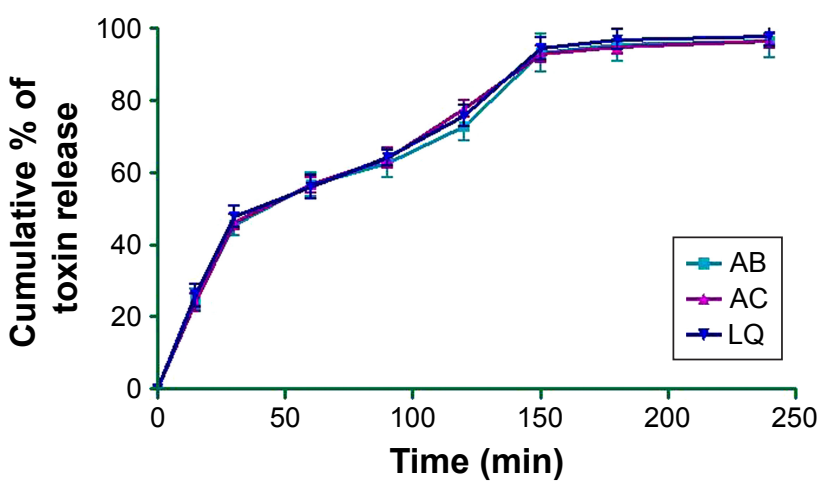

Figure I In vitro release of venoms from liposomal formulations of venoms $A B$, $A C$, and $L Q$.

Notes: The cumulative venom release in normal saline was determined from the liposomal formulation. The amount of venom released was measured at various time intervals up to $6 \mathrm{~h}$. There was a burst release of the venoms (AB, AC, and LQ) during the first $30 \mathrm{~min}$; after that, the release rate followed a gradual increasing trend up to $150 \mathrm{~min}$. The plateau was observed after $2.5 \mathrm{~h}$, which could be due to the equilibration developed between venom concentration (donor) and the receptor compartments.

Abbreviations: AB, Androctonus bicolor; AC, Androctonus crassicauda; LQ, Leiurus quinquestriatus.

\section{Morphological studies of the liposomes}

\section{Scanning electron microscope}

For the morphological study, the liposomal sample was diluted to separate liposomal entities. SEM micrographs of the liposomes in the presence of all three venoms demonstrate that they had a smooth surface and an ovoid or spherical shape and existed mainly as single unilamellar vesicles (SUVs; Figure 2). Additionally, liposomes were nonaggregated, and some of the liposomes appeared as multilamellar vesicles (MLVs) with a relatively larger size.

\section{Transmission electron microscope}

As shown in Figure 3, the morphological study by TEM demonstrated that the liposomes had a uniform size. The uniformity in size of the liposomes leads to less variation in venom release and minimizes dose fluctuation. The liposomes with a higher concentration of lipids had the larger
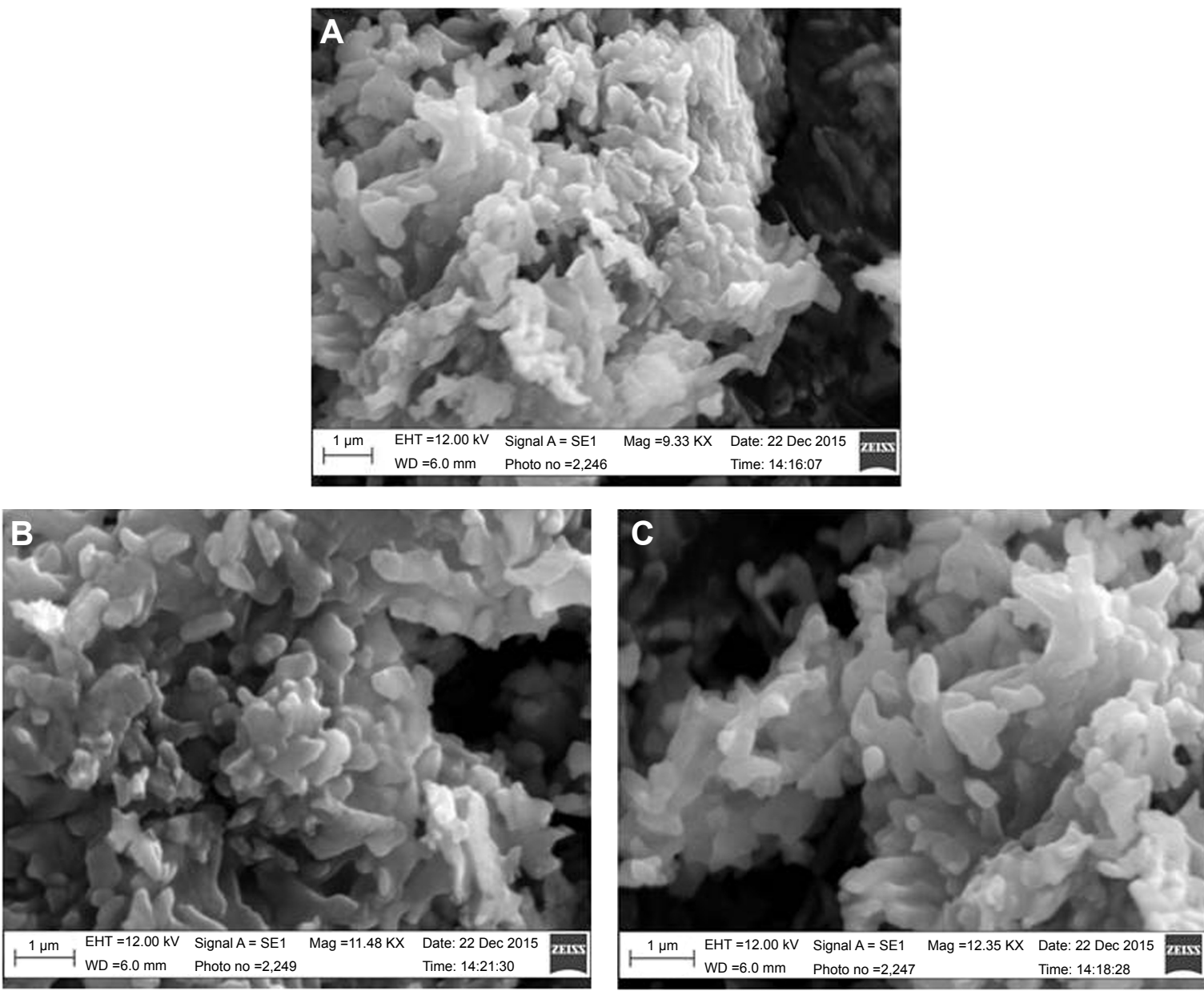

Figure 2 SEM micrograph of liposomes containing $A B$ venom (A), AC venom (B), and LQ venom (C).

Note: As shown in the figure, the lyophilized and dried liposomes when viewed under SEM after processing were found to have a smooth and an unruptured surface. Abbreviations: AB, Androctonus bicolor; AC, Androctonus crassicauda; LQ, Leiurus quinquestriatus; SEM, scanning electron microscope. 

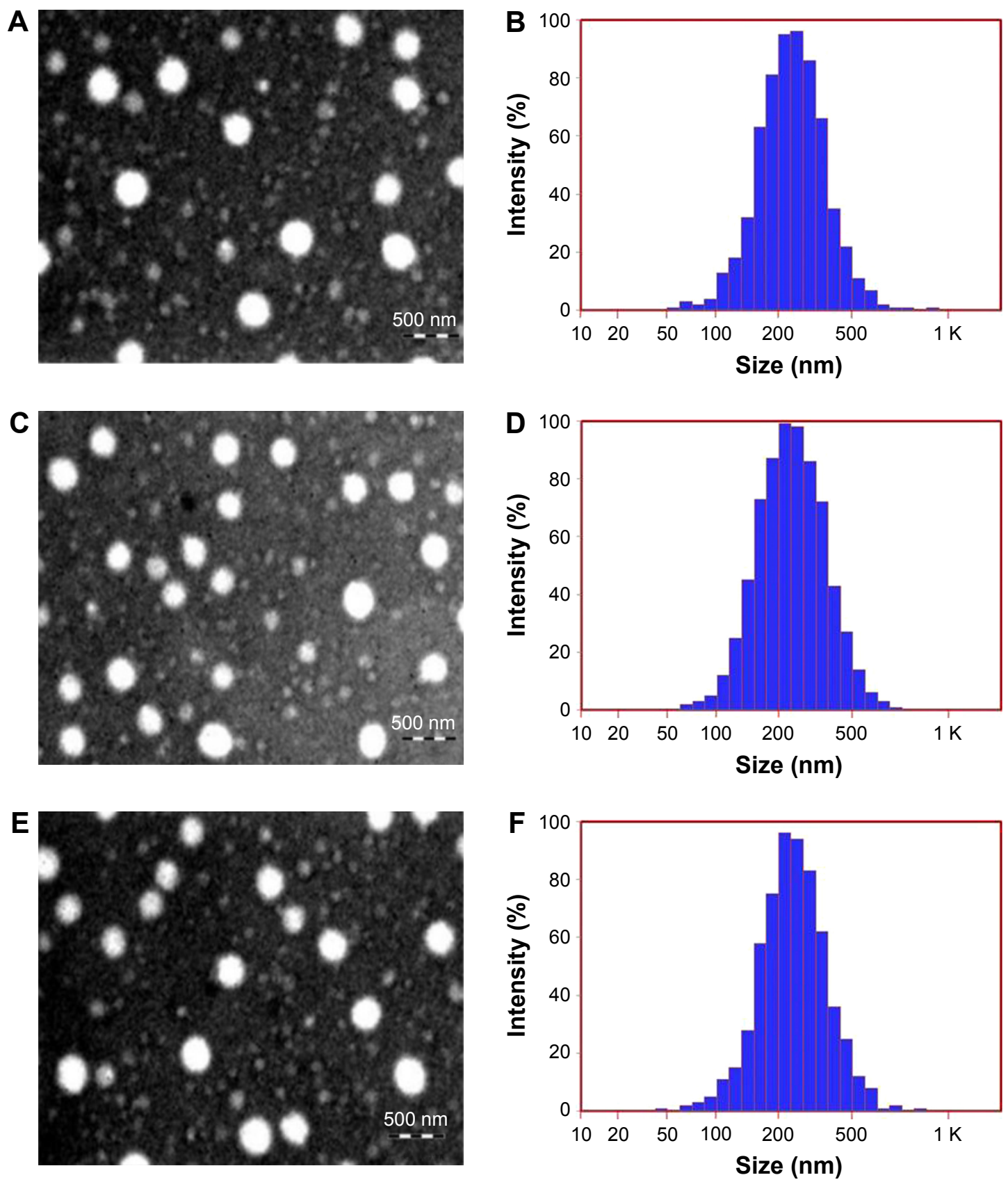

Figure 3 TEM photographs of liposomal formulations of venoms.

Notes: (A), (C), and (E) show the TEM images and (B), (D), and (F) represent the DLS histograms for the liposomes containing venoms AB, AC, and LQ, respectively. TEM photographs demonstrate that the prepared liposomes had a uniform size and mostly existed as unilamellar vesicles. However, a few of the liposomes were observed to be multilamellar with a larger size. Magnification: $\times 50,000$. Scale bar $=500 \mathrm{~nm}$.

Abbreviations: AB, Androctonus bicolor; AC, Androctonus crassicauda; DLS, dynamic light scattering; LQ, Leiurus quinquestriatus; TEM, transmission electron microscope.

size; however, as the concentration of lipids decreases, this ultimately results in the formation of smaller sized liposomes. Most of the liposomes observed through the microscope were unilamellar (data not shown). Figure 3 shows the formula chosen for the study, which has been determined to have the smallest size. The smallest size is due to the lipid in this formulation.

\section{Particle size, PDI, and zeta potential}

The liposomal size of the formulation was determined by photon correlation spectroscopy that analyzes the fluctuations by light scattering due to the Brownian motion of the particles. The particle size of the $\mathrm{AB}$ liposomes $(>90 \%)$ was found to be $235.8 \pm 12.5 \mathrm{~nm}$, whereas for AC and LQ liposomes, it was $243.8 \pm 9.8 \mathrm{~nm}$ and $238.6 \pm 7.5 \mathrm{~nm}$ respectively. The zeta 
potential for $\mathrm{AB}, \mathrm{AC}$, and $\mathrm{LQ}$ formulations was found to be $-22 \pm 3.2,-19 \pm 2.5$, and $-23 \pm 2.3 \mathrm{mV}$ respectively, which was optimum to make liposomes segregated. Additionally, we also determined the PDI (a measure of uniformity in liposomes' size), which was found to be $0.27 \pm 0.04$, $0.24 \pm 0.05$, and $0.28 \pm 0.06$ for the formulations $\mathrm{AB}, \mathrm{AC}$, and LQ, respectively.

\section{Stability studies of the liposomes}

The data for the stability measurements of the liposomes are shown in Table 2. No change was observed in the vesicles size and $\mathrm{EE}$ of the liposomes stored at $4{ }^{\circ} \mathrm{C}$, whereas a minor $(P>0.05)$ change in the EE was observed in the liposomes at the end of the fourth week of storage. Liposomes stored at $4{ }^{\circ} \mathrm{C}$ were able to retain a higher percentage of venom up to a period of 4 weeks. Furthermore, no sedimentation, aggregation, or change in color were observed in the prepared formulation over a period of 12 weeks at $25^{\circ} \mathrm{C}$. These observations demonstrate that all the venom liposomal formulations were stable and free from early degradation.

\section{In vitro anti-cancer activity Cell viability assay}

The cell survival analysis was performed on Muse Cell Analyzer as described in the Materials and methods section. A significant reduction in cell survival was noticed in the HCT-8 cancer cell line when treated with two different concentrations (150 and $200 \mu \mathrm{g} / \mathrm{mL}$ ) of the free and liposomalencapsulated venom. Interestingly, we observed a remarkable decrease in cell population when the cell line was exposed to encapsulated venom in the liposomes. The event has been shown in the form of histogram and bar graph (Figure 4). The rationale behind selecting these two concentrations is based on our preliminary studies in a cell survival assay. We observed that at concentration $<100 \mu \mathrm{g} / \mathrm{mL}$, cells did not show any effect and the concentration $>200 \mu \mathrm{g} / \mathrm{mL}$ damaged the cells badly (data not shown). In the case of venom AB, the encapsulated formulations significantly reduced the cell population as compared to lipid control and FV treatments $(P<0.05)$. The reduction in the cell number was as low as $60 \%$ as compared to control, in which the cell survival was close to $90 \%$. However, the free form of venom AB did not demonstrate any significant inhibitory effect. Furthermore, the encapsulated venoms AC and LQ also dramatically reduced $(P<0.05)$ the cell viability when HCT-8 was treated with the aforesaid concentrations (Figure 4). Hence, it can be concluded that the decrease in the cell viability was in proportion to the increase in venom concentration and encapsulation of the venom.

\section{Oxidative stress}

As reported earlier, the scorpion venom treatment causes severe phenotypic changes in the HCT- 8 cell line. ${ }^{1}$ In this study, we elaborated the previous findings by modifying the venom treatment strategies. We treated the cells with either FV or the venom encapsulated in liposome. Once treated, we measured the ROS by the Muse Cell Analyzer using the kit (Cat No MCH 100111-2). A remarkable increase in ROS was observed in FV- and encapsulated venom-treated cell line (Figure 5). However, the HCT-8 cells treated with encapsulated venom showed a significantly higher percentage of ROS generation as compared to FV treatment and control. As shown in Figure 5, the histograms of ROS obtained after the treatment of venom were divided into two distinct zones, namely, M1 and M2. The M1 phase shows low ROS-specific stained cells and hence is designated as $\operatorname{ROS}(-)$, while the M2 phase that has a higher concentration of ROS-positive stained cells has been denoted as ROS (+). After venom treatment, we found that M2 was > M1 in the HCT-8 cell line. The encapsulated $A B$ venom showed $20 \%$ increase in ROS generation when compared to venom alone at a concentration of $150 \mu \mathrm{g} / \mathrm{mL}$, whereas at a higher concentration $(200 \mu \mathrm{g} / \mathrm{mL})$, an increase in the percentage of ROS generation was

Table $2 \mathrm{EE}$ and vesicle size of the prepared liposomes during storage at $4^{\circ} \mathrm{C}$ for 4 weeks and $25^{\circ} \mathrm{C}$ over a period of 3 months

\begin{tabular}{|c|c|c|c|c|c|c|c|}
\hline \multirow[t]{2}{*}{ Time } & \multicolumn{3}{|c|}{ EE (\%), mean \pm SD } & \multicolumn{3}{|c|}{ Particle size $(\mathrm{nm})$, mean \pm SD } & \multirow{2}{*}{$\begin{array}{l}\text { Discoloration } \\
\text { sedimentation } \\
\text { aggregation }\end{array}$} \\
\hline & $\overline{\mathrm{AB}}$ & AC & LQ & $\overline{\mathrm{AB}}$ & AC & LQ & \\
\hline \multicolumn{8}{|l|}{$4^{\circ} \mathrm{C}$} \\
\hline 2 weeks & $54.5 \pm 2.5$ & $52.3 \pm 2.4$ & $51.9 \pm 3.4$ & $232.4 \pm 10.2$ & $243.8 \pm 9.8$ & $238.6 \pm 7.5$ & $x$ \\
\hline 4 weeks & $54.2 \pm 3.2$ & $52.1 \pm 2.5$ & $51.2 \pm 3.2$ & $235.7 \pm 8.4$ & $243.5 \pm 5.9$ & $237.5 \pm 9.5$ & $x$ \\
\hline \multicolumn{8}{|l|}{$25^{\circ} \mathrm{C}$} \\
\hline I month & $53.8 \pm 4.2$ & $51.8 \pm 3.5$ & $50.8 \pm 2.8$ & $236.5 \pm 7.5$ & $245.9 \pm 6.8$ & $239.4 \pm 8.5$ & $x$ \\
\hline 2 months & $53.2 \pm 3.4$ & $51.1 \pm 2.4$ & $49.8 \pm 3.5$ & $237.6 \pm 8.5$ & $248.6 \pm 9.5$ & $239.8 \pm 10.5$ & $x$ \\
\hline 3 months & $52.4 \pm 5.2$ & $50.1 \pm 4.2$ & $49.2 \pm 5.4$ & $238.6 \pm 8.8$ & $248.4 \pm 10.5$ & $242.8 \pm 7.4$ & $x$ \\
\hline
\end{tabular}

Note: "x" represents absent or not found.

Abbreviations: AB, Androctonus bicolor; AC, Androctonus crassicauda; EE, encapsulation efficiency; LQ, Leiurus quinquestriatus. 
A

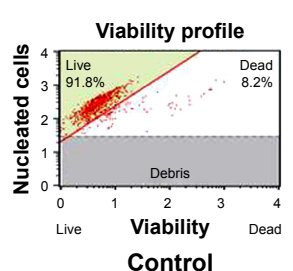

Control

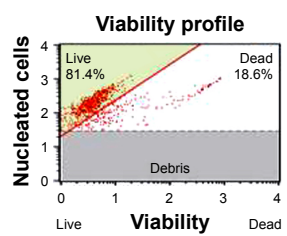

150 LV

C
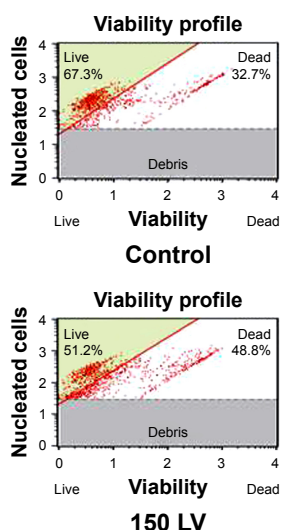

E

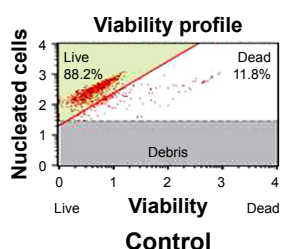

Control

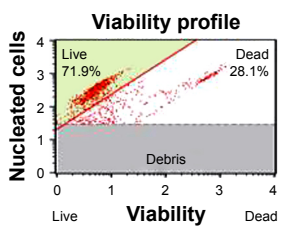

150 LV
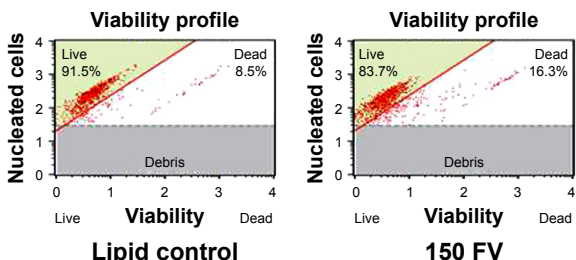

Viability profile
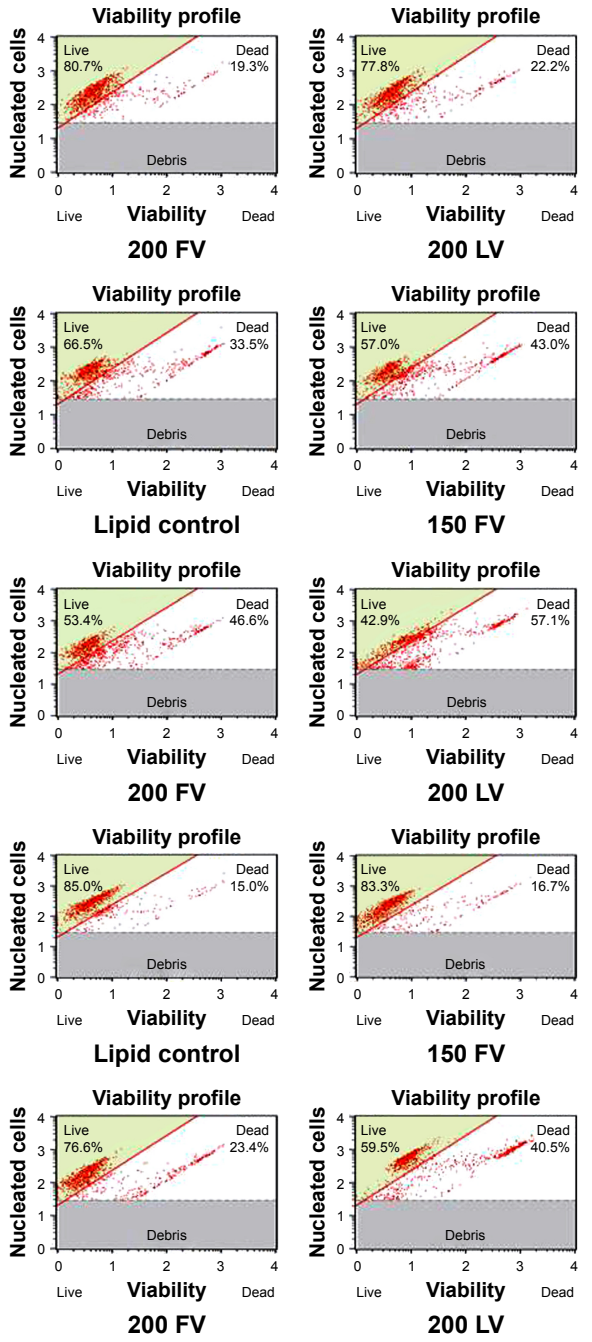

B

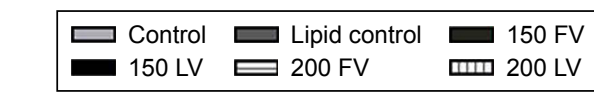

FV

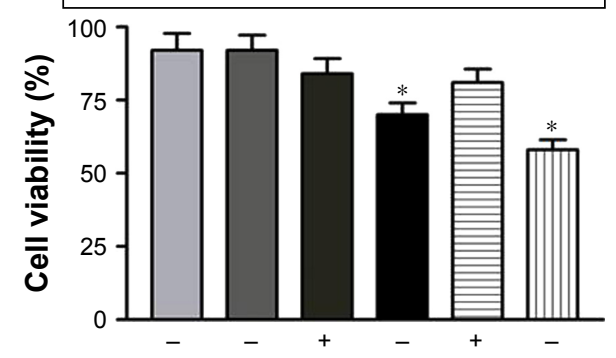

Encapsulated venom -

Lipid

D

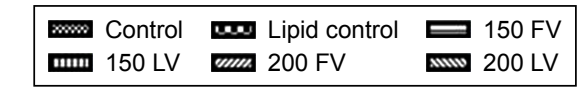

FV

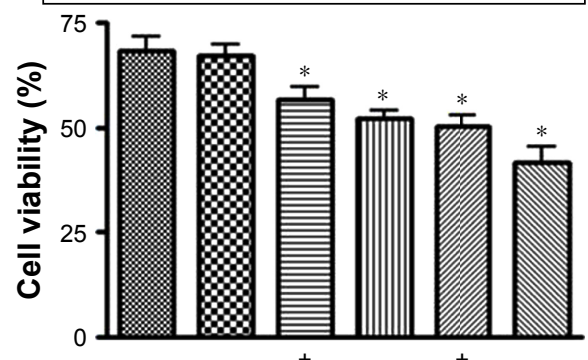

Encapsulated venom -

Lipid

$\mathbf{F}$
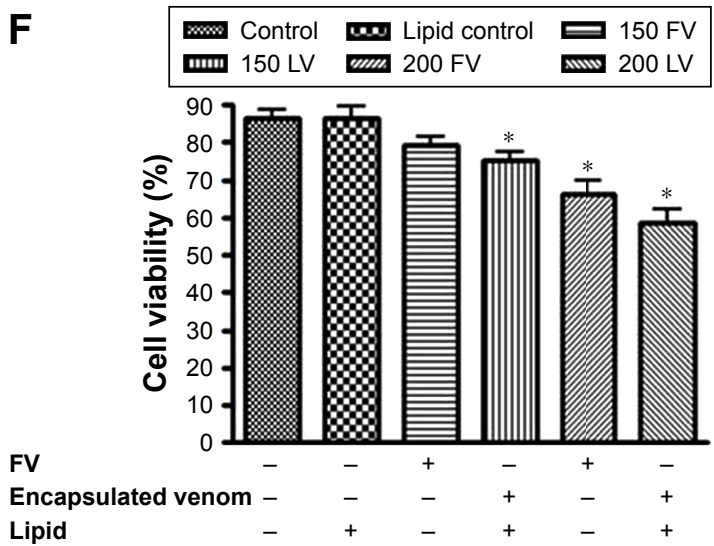

Figure 4 Cell survival assay: HCT-8 cells were treated with different concentrations of free and liposomal scorpion venoms (AB, AC, and LQ) for 24 h.

Notes: The cells cultured in either DMEM media (control) or media with lipid (lipid control) were used. Equal numbers of cancer cells in $20 \mu \mathrm{L}$ were taken into $380 \mu \mathrm{L}$ of cell counting solution and counted on Muse Cell Analyzer. Histograms (A), (C), and (E) show the status of live and dead cells, and quantitative analyses are presented in the form of bar graphs (B), (D), and (F) for venoms AB, AC, and LQ, respectively. There was a significant reduction in cell viability upon free and liposomal-encapsulated venom treatment as compared with control, and lipid control. *Statistically significant $(P<0.05)$.

Abbreviations: AB, Androctonus bicolor; AC, Androctonus crassicauda; DMEM, Dulbecco's Modified Eagle's Medium; FV, free venom; LQ, Leiurus quinquestriatus; LV, liposomal venom.

observed, which was found to be $33 \%$. A similar pattern of ROS increment was also observed when HCT-8 cells were treated with encapsulated venom LQ in comparison to the FV. The ROS increment, in this case, was found to be $60.5 \%$ and $114 \%$ at lower and higher doses, respectively. Furthermore, the LV AC also demonstrated an increase in the ROS generation; however, the pattern was found to be altered. In this treatment, the difference in ROS generation at a lower concentration was found to be $60.5 \%$; however, at a higher concentration, it was $34.95 \%$. The altered behavior in ROS generation at a higher concentration of venom could be attributed to the differential uptake of venom by the cells in this particular setup of the experiment.

\section{Apoptosis assay}

The Muse Cell Analyzer determined the extent of apoptosis in HCT-8 cell lines treated with liposome containing scorpion venom, treated using the Annexin V staining kit. As shown in 
A
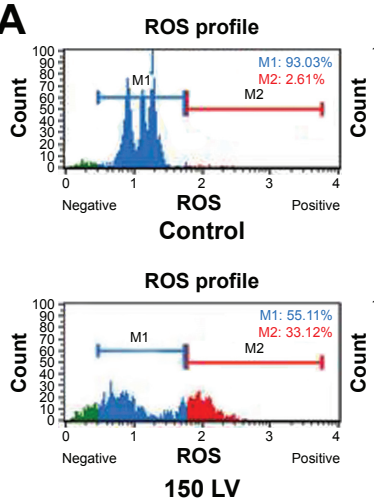

C
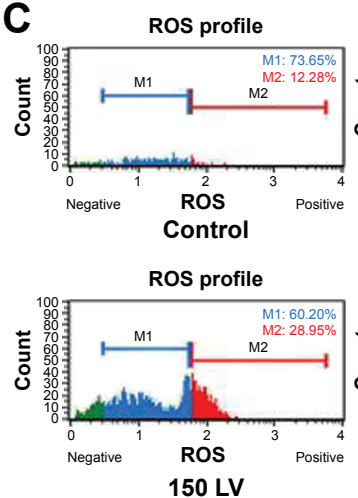

$150 \mathrm{LV}$

E

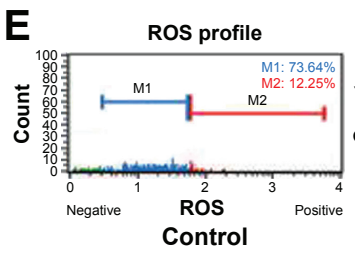

ROS profile

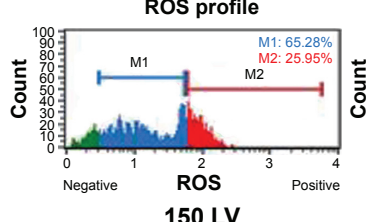

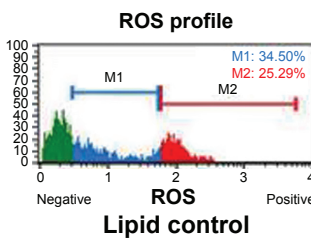

ROS profile

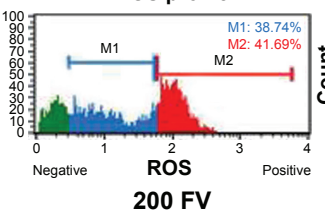

200 FV
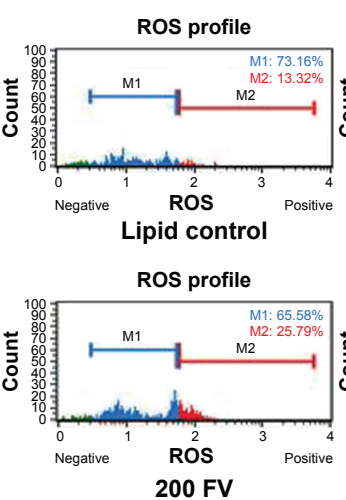

$200 \mathrm{FV}$
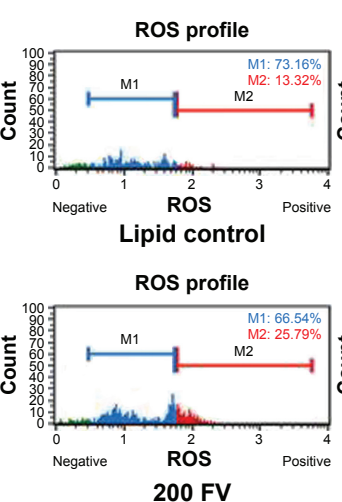
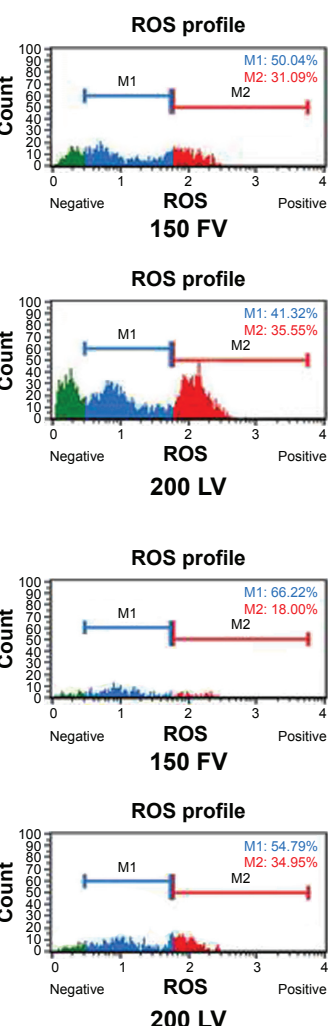

200 LV
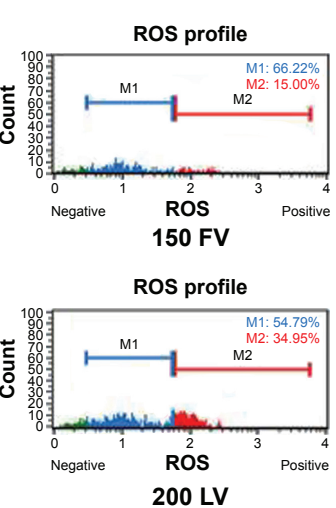

B

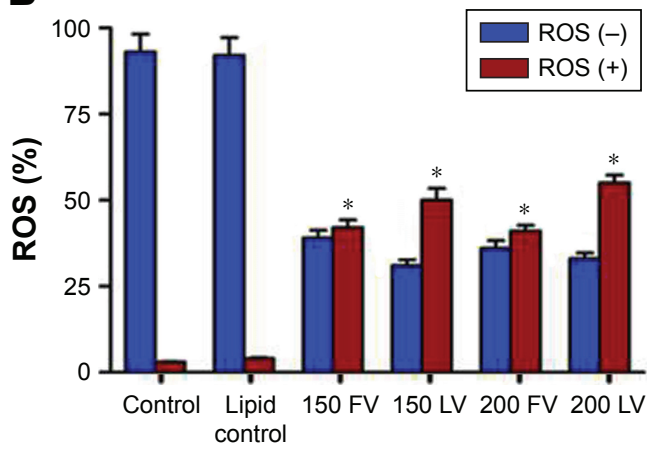

D

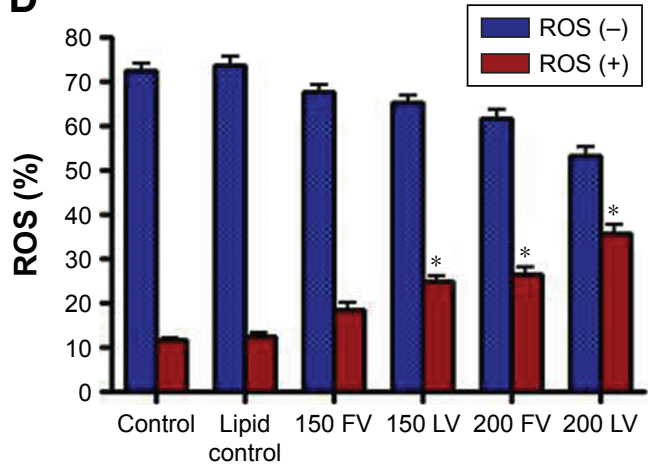

$\mathbf{F}$

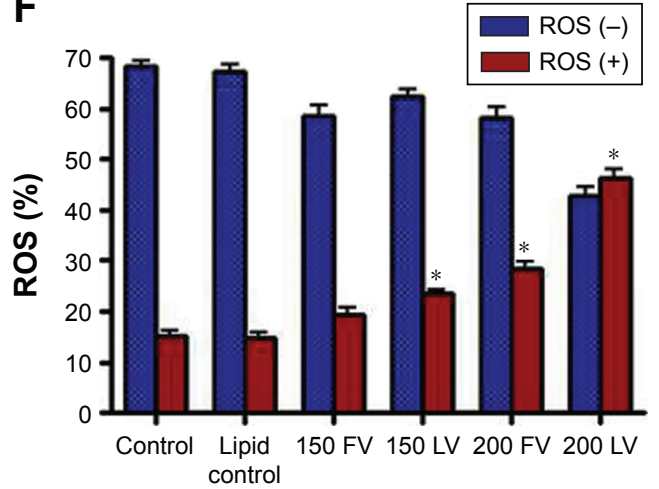

Figure 5 Oxidative stress: the ROS generation on HCT-8 cell line after challenging with free and encapsulated scorpion venoms was determined on Muse Cell Analyzer. Notes: All the cells showing positive staining are referred to as ROS (+), while the cells that do not stain with the ROS-specific dye used from the kit are referred to as ROS (-). Histograms (A), (C), and (E) show the ROS formation in control and venom-treated samples AB, AC, and LQ, respectively. Statistical analyses of the data are depicted in the form of bar graphs (B), (D), and $(\mathbf{F})$. Data are reported as mean $\pm S D(n=3)$ from three independent experiments. It is clear from the observations that the number of positive cells (ROS+) is more after venom treatment as compared to control. *Statistically significant; $P<0.05$ as compared to control and lipid control.

Abbreviations: ROS, reactive oxygen species; FV, free venom; LV, liposomal venom.

Figure 6, the rate of apoptosis increased proportionally with the venom concentration in unencapsulated and encapsulated venoms. We observed a sizable number of early apoptotic cells when treated with FV, and encapsulated venom as well, when compared to control $(P<0.05)$. The number of apoptotic cells increases from $\sim 25 \%$ to $\sim 50 \%$ for the encapsulated venom $\mathrm{AB}$ when compared with the $\mathrm{FV}$ at a higher concentration $(200 \mu \mathrm{g} / \mathrm{mL})$. A similar increase in early apoptotic cells in HCT-8 cells was also observed when this line was treated with the encapsulated venoms AC and LQ $(P<0.05)$.
As expected, the venoms in an encapsulated form showed statistically higher apoptotic cells upon treatment.

\section{Cell cycle assay}

To explicate the mechanism of reduced cell survival and increased apoptosis, the effects of FV and encapsulated venoms (AB, AC, and LQ) were investigated on cell cycle progression. HCT-8 cells were treated with different concentrations of venoms for $24 \mathrm{~h}$. At the termination of the experiment, the cell cycle distribution analysis was performed 


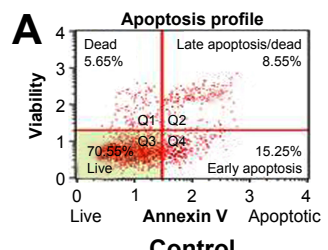

Control
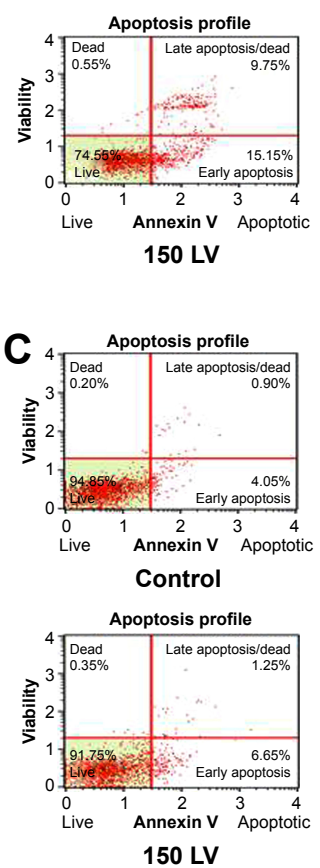

E

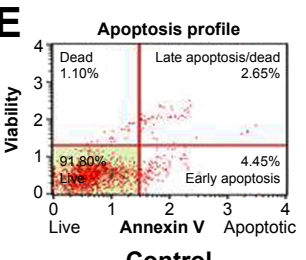

Control

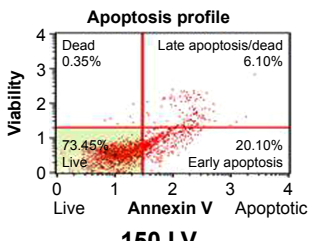

$150 \mathrm{LV}$

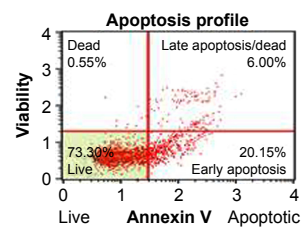

Lipid control
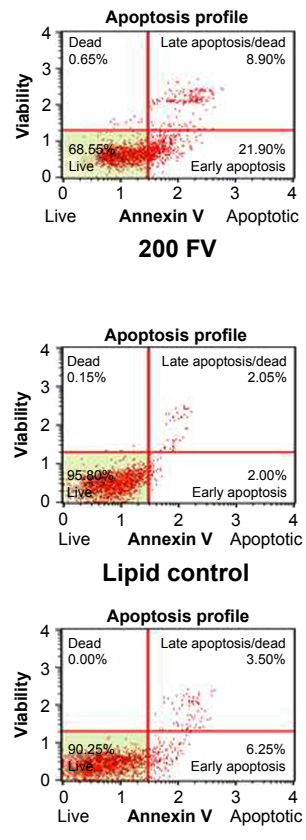

200 FV

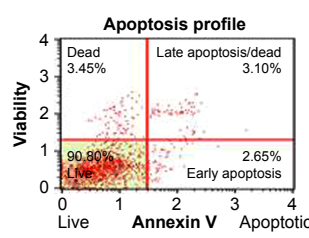

Lipid control

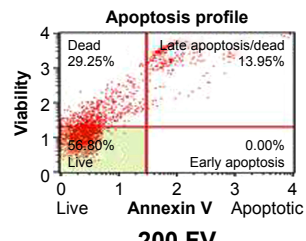

200 FV
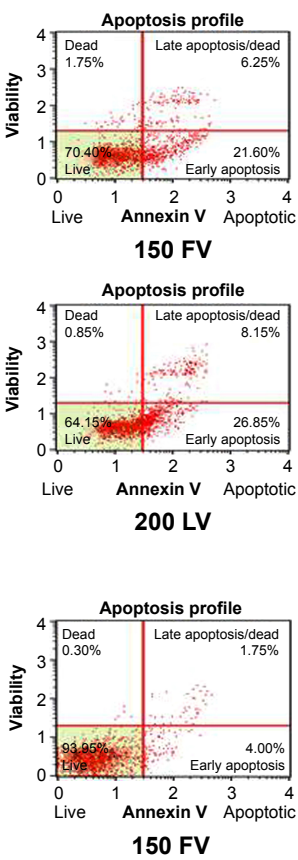

$150 \mathrm{FV}$

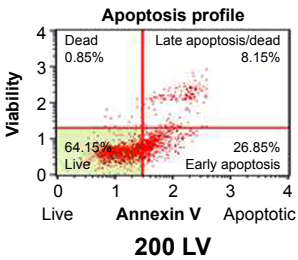

200 LV

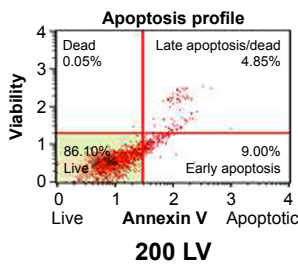

FV

Encapsulated venom -

Lipid

$F$

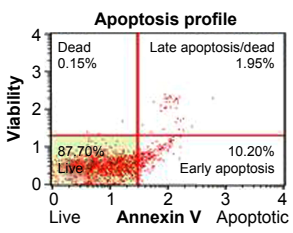

$150 \mathrm{FV}$

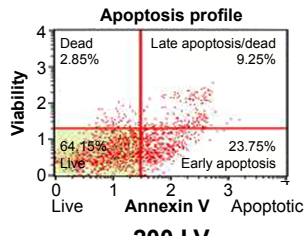

B
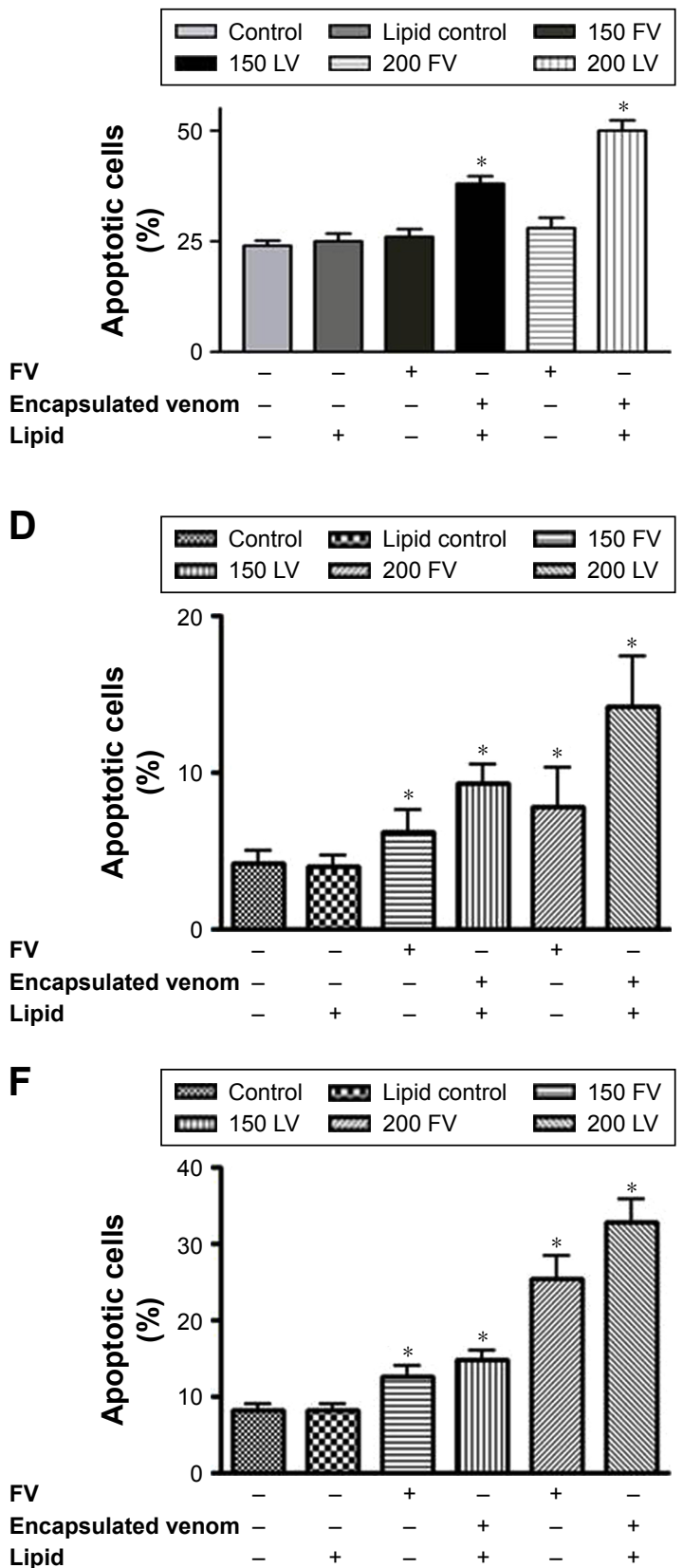

Figure 6 Apoptosis assay: the rate of apoptosis was measured in control and venom-treated HCT-8 cell line by Annexin $\mathrm{V}$ staining.

Notes: In apoptosis profile, Q1 represents dead cells, Q2 represents late apoptotic cells, Q4 represents early apoptotic cells, and Q3 represents live cells (histograms (A), $(\mathbf{C})$, and $(\mathbf{E})$ for the venoms $A B, A C$, and LQ, respectively). The mean $(n=3)$ percentage of total apoptotic cells $(\mathrm{Q} 2+\mathrm{Q} 4)$ was calculated and is shown in the bar graphs for HCT-8 cell lines for all three venoms (columns (B), (D), and (F)). A significant number of apoptotic cells were observed upon the encapsulated venom treatment as compared with control and lipid control. *Statistically significant $(P<0.05)$.

Abbreviations: AB, Androctonus bicolor; AC, Androctonus crassicauda; FV, free venom; LQ, Leiurus quinquestriatus; LV, liposomal venom; Q, quadrant.

on Muse Cell Analyzer. As shown in Figure 7, the G0/G1 enrichment was remarkably higher upon venom treatment in this cell line. It varied from $13.5 \%$ (control) to $43.6 \%$ (venom-liposome) for the cells treated with formulation containing $\mathrm{AB}$ venom, whereas it ranged from $12.7 \%$ (control) to $27.4 \%$ for AC-treated cells and $10 \%$ (control) to $38 \%$ for LQ-treated cells. In conclusion, our result demonstrates a perceptible increase in $\mathrm{G} 0 / \mathrm{G} 1$ accumulation when the HCT-8 cell line was treated with encapsulated venom as compared to its free counterpart (Figure 7).

\section{Discussion}

Scorpion venoms contain various proteins and peptides that act as an anti-cancer agent. These proteins and peptides 
A

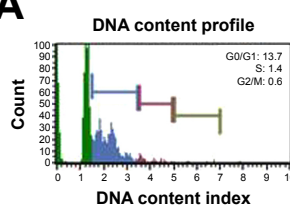

Control

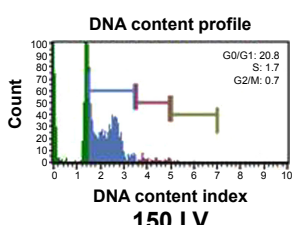

150 LV

C DNA content profile

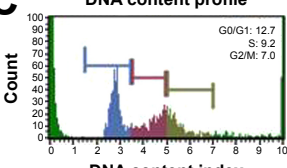

DNA content index

Control

DNA content profile

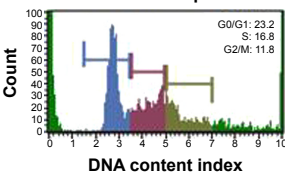

150 LV

E

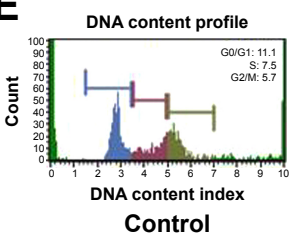

NA content profile

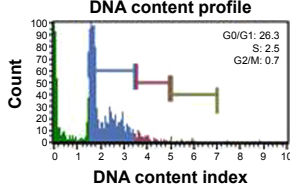

$150 \mathrm{LV}$

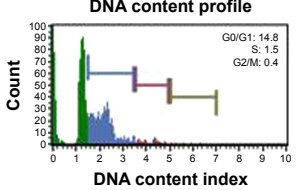

Lipid control

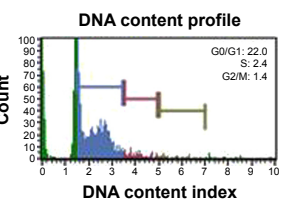

200 FV

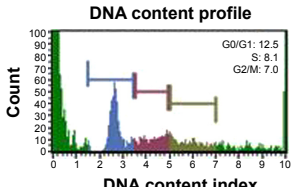

DNA content index
ipid control

DNA content profile

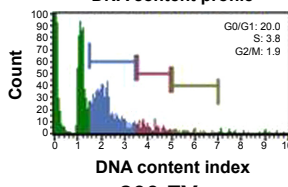

200 FV
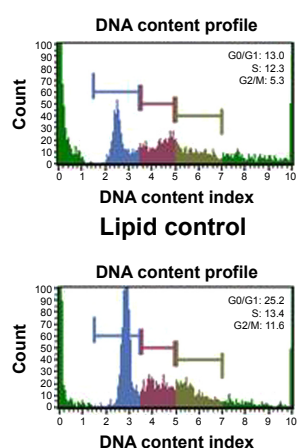

200 FV

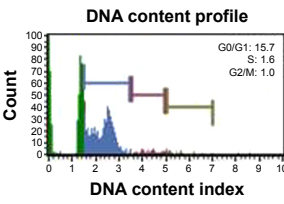

$150 \mathrm{FV}$

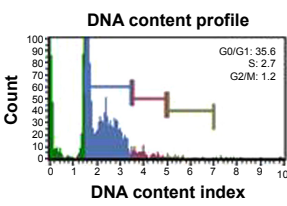

200 LV

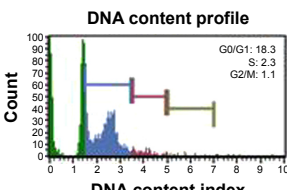

$150 \mathrm{FV}$

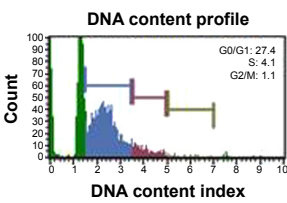

200 LV

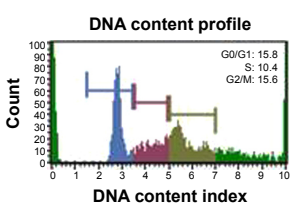

$150 \mathrm{FV}$

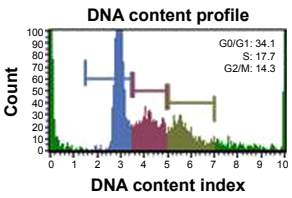

200 LV

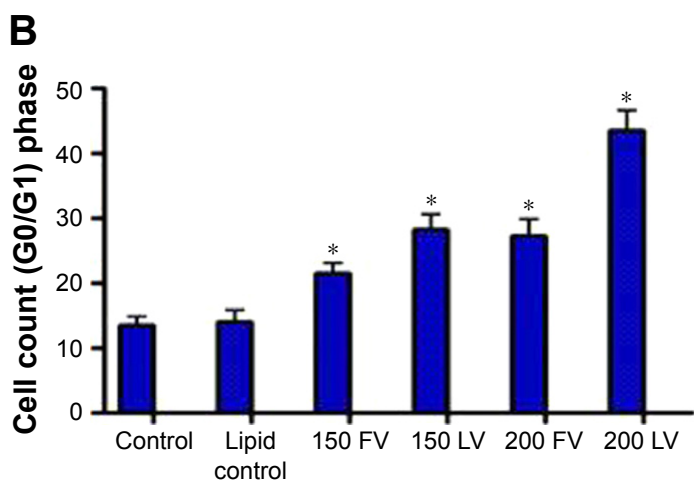

D

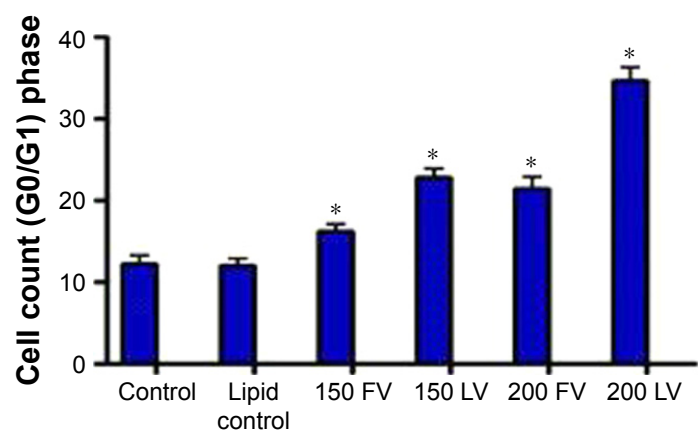

F

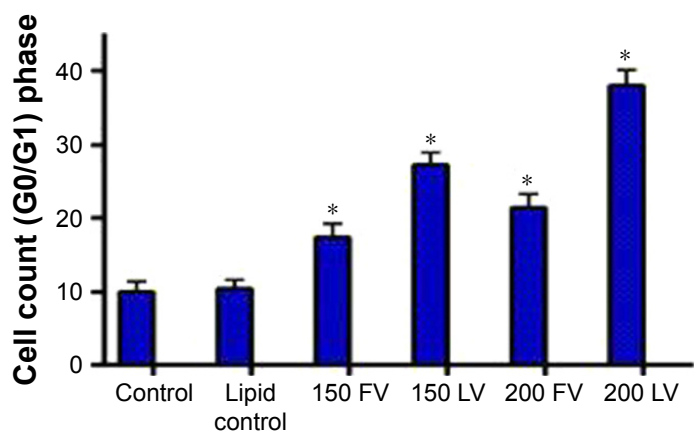

Figure 7 Cell cycle assay: analysis of cell cycle arrest in free and encapsulated scorpion venom for all three formulations (AB, AC, and LQ) treated with HCT-8 cell line was performed.

Notes: Cells were treated with different concentrations of FV and LV. The findings are presented in the form of histograms $(\mathbf{A}),(\mathbf{C})$, and $(\mathbf{E})$ and bar graphs $(\mathbf{B})$, (D), and $(\mathbf{F})$ for venoms $A B, A C$, and $L Q$, respectively. A significant $G 0 / G I$ enrichment was observed in $F V$ - and encapsulated venom-treated cell line. *Statistically significant ( $P<0.05)$. Abbreviations: AB, Androctonus bicolor; AC, Androctonus crassicauda; FV, free venom; LQ, Leiurus quinquestriatus; LV, liposomal venom.

inhibit cell proliferation and growth in vitro by interacting with different molecules involved in the signal transduction pathway. ${ }^{17}$ This study is in continuation of our previously published work. ${ }^{17}$ Currently, we have developed a mechanism to make scorpion venom more efficient against colorectal cancer cell line by adopting the nanomedicine approach. We studied the effect of nanoformulations on cell viability, ROS generation, programmed cell death (cell apoptosis), and cell cycle arrest on a well-established and characterized HCT-8 colorectal cancer cell line. Furthermore, the lipids chosen for the formulation of liposomes were, namely, DSPC and cholesterol. These lipids are safe ingredients and are obtained from natural sources. They are biodegradable and nontoxic agents and act as a dispersant, preventing coagulation, sedimentation, or aggregation of the formulation, thus improving the stability of the formulations. ${ }^{29}$ Cholesterol modulates the fluidity of the lipid bilayers by preventing crystallization of the acyl chain of phospholipid and providing steric hindrance to their movement, thus increasing the consistency of the vesicles in the presence of blood proteins and reducing the permeability of the liposomal lipid layer to enclose the drugs.

The vesicles were prepared using different ratios of lipids and cholesterol. The concentration of TBA and purified/double- 
distilled water was kept constant. On the other hand, EE is an important parameter in the case of liposome formulations as it may affect the venom release and thus may influence the efficacy of the formulation. In all the preparations, the formulation VL6 showed high EE\% approaching 56\% with an optimal liposomal size of $235.8 \pm 12.5 \mathrm{~nm}$ (Table 1). The high EE\% of VL6 may be attributed to the presence of optimum DSPC and cholesterol ratios that enhance the vesicle elasticity and flexibility, rendering the liposomal membrane able to encapsulate large amounts of the venom. Low lipid level works ideally for this method because lipid, cholesterol, and TBA ratio were the key factors affecting the size of the liposomes and the polydispersity of the preparation. The liposomes produced in this study using DSPC and cholesterol were found to possess good EE. A value of PDI, which is a measure of uniformity of liposome size within the formulation, was also calculated as described in the Materials and methods section. The liposomal formulation exhibited a narrow size distribution (PDI range $=0.24-0.28$ for all three formulations). The low PDI is an indicator of narrowly dispersed nanostructures without any aggregation in water. Our findings are well supported by the earlier reports of the liposomal preparations of uniform size and low PDI, which are ideal characteristic features of a novel lipid formulation. ${ }^{30}$ Furthermore, the zeta potential values of our formulation showed that the liposomes have sufficient negative charge to avoid aggregation due to strong electrostatic repulsion between vesicles, which is a favorable indicator of the stable liposome (Table 2). ${ }^{31}$

The size and shape of liposomes are critical parameters especially when the liposomes are intended for therapeutic use. The results of this study revealed that the venom release profile from all the three venom formulations was biphasic, with an initial fast venom release for $2 \mathrm{~h}$ followed by a plateau (Figure 1). In in vitro release, the profile appears to be dependent on the lipid composition, as DSPC formulations exhibit improved venom retention and sustained venom release. The venom release from liposomes is also controlled by their size, because the smaller liposomes had larger curvature and slacker lipid packing as compared to larger liposomes (Figures 2 and 3), which made them more vulnerable to be attacked by the biological components, resulting in the release of the encapsulated material at a faster rate. ${ }^{32}$ The results of this study clearly suggest that the venom release from liposomes follows zero-order kinetics, meaning thereby that it is independent of the venom concentration in liposomes.

As discussed earlier, the liposomes are being widely studied for enhancing the efficacy of venoms because of the nontoxic nature of the lipids. Furthermore, the lipid bilayers and the aqueous core of liposomes can also serve as a reservoir for the drug or venoms. ${ }^{22-24}$ This established phenomenon was the driving force to undertake this approach of venom encapsulation and correlates well with the objective of this study, which is to enhance the already reported anticancer activity of the scorpion venom ${ }^{17}$ through liposomal drug delivery approach, on HCT-8 cells. Scorpion venoms $\mathrm{AB}, \mathrm{AC}$, and LQ dramatically reduced the cell survival of colorectal cancer cells (Figure 4). Our study shows that many characteristic features, which are also the hallmarks of cancer progression, changed when the cells were treated with scorpion venoms. Furthermore, one of the toxic effects of venoms was an increase in the ROS, resulting in the enhancement of apoptosis in cancer cells, which was helpful in destroying the tumor cells and sequestering metastasis. Furthermore, it is a well-established phenomenon that ROS are responsible for the induction of apoptosis in cancer cells. ${ }^{33-35}$ We have demonstrated an increase in the number of apoptotic cells upon encapsulated scorpion venom treatments. Additionally, ROS are also known to damage DNA and alter drug sensitivity in cancer. ${ }^{36}$ While cells are under stress due to the presence of scorpion venoms, the phenomenon of DNA damage is amplified multifold.

Apoptosis is one of the manifestations of higher ROS production; hence, to correlate the higher ROS in venomtreated samples with enhanced apoptotic cells, we examined the extent of apoptosis in these samples. Statistical analyses of the results are illustrated in the form of histograms and bar graphs (Figure 5). As shown in Figure 6, the encapsulated venom noticeably increased the apoptosis in the colorectal cancer cell line. On the other hand, the free form of venom $\mathrm{AB}$ showed insignificant anti-cancer activity against the HCT-8 cells. Our results correlate well with the presence of high ROS, with increased number of apoptotic cells in venom-treated HCT-8 cells.

Additionally, in this study, we observed a significant G0/G1 enrichment in cells treated with FV and encapsulated venoms in the colorectal cancer cell line (Figure 7). We found that venoms alone or encapsulated in liposomes inhibited the growth of colon carcinoma cells in a concentration-dependent manner. Similar findings have been reported in a study on growth inhibition of breast cancer cells with snake venom. ${ }^{37}$ The phenomenon of cell cycle arrest has been used as a therapeutic tool to inhibit tumor progression in in vitro studies. ${ }^{38}$ The mechanism for reduced DNA replication could be attributed to the "shutting down" of some cancer survival trails, including the NF- $\mathrm{KB}$ signaling cascade. In a recent study, it has been reported that the scorpion venom restricted cell 
progression, caused by the cell cycle arrest at the G0/G1 phase, and restricted the production of cell cycle regulatory protein cyclin D1 in in vitro human leukemia cells. ${ }^{39}$ The venom also suppressed the constitutive NF- $\mathrm{\kappa B}$ activation through restriction of the phosphorylation and breakdown of $\mathrm{I} \kappa \mathrm{B} \alpha{ }^{39}$

Taken together, the findings such as low cell survival, higher ROS and apoptosis, and cell cycle arrest strongly suggest the anti-cancer potential of scorpion venoms used in this study. This study further suggests that the venom efficiency increased multifold when utilized in the encapsulated form. In recent years, much work has been done on the intracellular efficient delivery of protein/macromolecules, as their lipophobic and charged nature with high molecular weight makes cell membrane passage tough to reach the target sites. Furthermore, these molecules often have poor pharmacokinetic and biodistribution properties and are highly vulnerable to degradation by extra- and intracellular enzymes. ${ }^{40}$ In previous studies, liposomes have shown efficacy to improve the therapeutic effectiveness of labile macromolecular drugs. Additionally, these carriers are reported to improve pharmacokinetics, provide protection from degradation, mediate targeting to the pathological site, and facilitate uptake by the target cells. ${ }^{41,42}$

In the same line of research on nanoparticles (NPs), when examined for their ability to suppress the growth of human larynx carcinoma cells, the venom peptide (ICD-85)-loaded NPs were found to be remarkably more potent than FV peptide. ${ }^{43}$ Furthermore, Piao et $\mathrm{al}^{44}$ reported the increased efficacy of cationic NPs, which carried tumor suppressor microRNA-107 approximately 800,000 times more than free miR in head and neck squamous cell carcinoma. In addition to this, numerous investigations have shown that nanoparticulate drug delivery systems can increase antitumor efficacy while reducing side effects. ${ }^{45,46}$ Therapeutic potentiality of the venom peptideloaded NPs was also investigated by MTT-based cell proliferation assay. MTT results showed a sharp discrimination in cell inhibition between FV peptide and venom peptide-loaded NPs, thus stressing the key role of the binding and internalization of NPs in the enhancement of anti-cancer activity. ${ }^{47,48}$ In summary, liposomal-based delivery of venoms enhances their anti-cancer potential on colon carcinoma cells in vitro. Our results demonstrate the potential application of liposomes as a carrier system for the delivery of venoms.

\section{Conclusion}

We have developed a natural lipid-based liposomal system for the delivery of scorpion venoms to enhance their anti-cancer activity. Venoms were easily loaded to the liposomes with good EE and sustained release phenomenon.
The nanovesicles were uniform in size with a smooth surface. Considering the negligible interference of liposomal lipids on the cytotoxicity of cancer cells, we can anticipate that venom-loaded liposomes have significantly enhanced anticancer efficacy on the HCT-8 cell line compared to a free form of venoms. Low cell survival, elevated ROS generation, high apoptosis, and G0/G1 enrichment were found to be statistically significant in the encapsulated venom-treated colorectal cancer cell line. Thus, it can be further concluded that the liposomes play a vital role in the rapidly developing field of nanomedicine for effective cancer treatment and drug delivery. The ease of liposomal preparation and improved efficacy of delivering the encapsulated molecules to the target site encouraged further detailed investigation of the nano-formulation on xenograft mouse model(s).

\section{Acknowledgment}

The authors would like to thank the Research Center of PSMMC Hospital and King Abdulaziz City for Science and Technology (KACST) for providing the necessary facilities and financial support.

\section{Disclosure}

The authors report no conflicts of interest in this work.

\section{References}

1. Poy D, Akbarzadeh A, Ebrahimi Shahmabadi H, et al. Preparation, characterization and cytotoxic effects of liposomal nanoparticles containing cisplatin: an in vitro study. Chem Biol Drug Des. 2016;88(4):568-573.

2. Vishvakrama P, Sharma S. Liposomes: an overview. J Drug Deliv Ther. 2014;4:47-55.

3. Tavano L, Muzzalupo R. Multi-functional vesicles for cancer therapy: the ultimate magic bullet. Colloids Surf B Biointerfaces. 2016;147:161-171.

4. Jeevanandam J, Chan YS, Danquah MK. Nano-formulations of drugs: recent developments, impact and challenges. Biochimie. 2016;128-129: 99-112.

5. Samad A, Sultana Y, Aqil M. Liposomal drug delivery systems: an update review. Curr Drug Deliv. 2007;4(4):297-305.

6. Spuch C, Navarro C. Liposomes for targeted delivery of active agents against neurodegenerative diseases (Alzheimer's Disease and Parkinson's Disease). J Drug Deliv. 2011;2011:469679.

7. Khodabandehloo H, Zahednasab H, Hafez AA. Nanocarriers usage for drug delivery in cancer therapy. Iran J Cancer Prev. 2016;9(2):e3966.

8. Mriouah JM, Nesbitt RL, Sosnowski D, et al. Fusogenic targeted liposomes as next-generation nanomedicine for prostate cancer. Cancer Res. 2016;76(14 suppl):2192.

9. Su Y, Xie Z, Kim GB, Dong C, Yang J. Design strategies and applications of circulating cell-mediated drug delivery systems. ACS Biomater Sci Eng. 2015;1(4):201-217.

10. Woodle MC, Storm G. Long Circulating Liposomes: Old Drugs, New Therapeutics. Austin, TX: RG Landes Co; 1998.

11. Slingerland M, Guchelaar H-J, Gelderblom H. Liposomal drug formulations in cancer therapy: 15 years along the road. Drug Discov Today. 2012;17(3):160-166.

12. Ramage G, Jose A, Sherry L, Lappin DF, Jones B, Williams C. Liposomal amphotericin B displays rapid dose-dependent activity against Candida albicans biofilms. Antimicrob Agents Chemother. 2013;57(5):2369-2371. 
13. Zhang X, Xie J, Li S, Wang X, Hou X. The study on brain targeting of the amphotericin B liposomes. J Drug Target. 2003;11(2):117-122.

14. Biswas A, Gomes A, Sengupta J, et al. Nanoparticle-conjugated animal venom-toxins and their possible therapeutic potential. I Venom Res. 2012;3:15.

15. Jain D, Kumar S. Snake venom: a potent anticancer agent. Asian Pac J Cancer Prev. 2012;13(10):4855-4860.

16. Harris JB, Scott-Davey T. Secreted phospholipases A2 of snake venoms: effects on the peripheral neuromuscular system with comments on the role of phospholipases A2 in disorders of the CNS and their uses in industry. Toxins. 2013;5(12):2533-2571.

17. Al-Asmari AK, Islam $\mathrm{M}, \mathrm{Al}$-Zahrani AM. In vitro analysis of the anticancer properties of scorpion venom in colorectal and breast cancer cell lines. Oncol Lett. 2016;11(2):1256-1262.

18. Alvarenga LM, Zahid M, Tommaso AD, et al. Engineering venom's toxin-neutralizing antibody fragments and its therapeutic potential. Toxins. 2014;6(8):2541-2567.

19. Deshane J, Garner CC, Sontheimer H. Chlorotoxin inhibits glioma cell invasion via matrix metalloproteinase-2. J Biol Chem. 2003;278(6): 4135-4144.

20. Li C, Liu M, Monbo J, et al. Turning a scorpion toxin into an antitumor miniprotein. J Am Chem Soc. 2008;130(41):13546-13548.

21. Gomes A, Bhattacharjee P, Mishra R, et al. Anticancer potential of animal venoms and toxins. Indian J Exp Biol. 2010;48(2):93-103.

22. Freitas T, Frézard F. Encapsulation of native crotoxin in liposomes: a safe approach for the production of antivenom and vaccination against Crotalus durissus terrificus venom. Toxicon. 1997;35(1):91-100.

23. Mandal M, Lee K-D. Listeriolysin O-liposome-mediated cytosolic delivery of macromolecule antigen in vivo: enhancement of antigenspecific cytotoxic $\mathrm{T}$ lymphocyte frequency, activity, and tumor protection. Biochim Biophys Acta. 2002;1563(1):7-17.

24. Fretz MM, Mastrobattista E, Koning GA, Jiskoot W, Storm G. Strategies for cytosolic delivery of liposomal macromolecules. Int J Pharm. 2005;298(2):305-309.

25. Al-Asmari AK, Riyasdeen A, Al-Shahrani MH, Islam M. Snake venom causes apoptosis by increasing the reactive oxygen species in colorectal and breast cancer cell lines. Onco Targets Ther. 2016;9:6485.

26. Bradford MM. A rapid and sensitive method for the quantitation of microgram quantities of protein utilizing the principle of protein-dye binding. Anal Biochem. 1976;72(1-2):248-254.

27. Chen J, Jiang H, Wu Y, Li Y, Gao Y. A novel glycyrrhetinic acidmodified oxaliplatin liposome for liver-targeting and in vitro/vivo evaluation. Drug Des Devel Ther. 2015;9:2265.

28. Öztürk E, Eroğlu M, Özdemir N, Denkbaş EB. Bioadhesive drug carriers for postoperative chemotherapy in bladder cancer. Adv Exp Med Biol. 2004;553:231-242.

29. Mozafari M. Nanoliposomes: preparation and analysis. Methods Mol Biol. 2010;605:29-50.

30. Haeri A, Alinaghian B, Daeihamed M, Dadashzadeh S. Preparation and characterization of stable nanoliposomal formulation of fluoxetine as a potential adjuvant therapy for drug-resistant tumors. Iran J Pharm Res. 2014;13(suppl):3.

31. Ali MFM, Salem HF, Abdelmohsen HF, Attia SK. Preparation and clinical evaluation of nano-transferosomes for treatment of erectile dysfunction. Drug Des Devel Ther. 2015;9:2431.

32. Nagayasu A, Uchiyama K, Kiwada H. The size of liposomes: a factor which affects their targeting efficiency to tumors and therapeutic activity of liposomal antitumor drugs. Adv Drug Deliv Rev. 1999;40(1): $75-87$.
33. Matés JM, Sánchez-Jiménez FM. Role of reactive oxygen species in apoptosis: implications for cancer therapy. Int J Biochem Cell Biol. 2000; 32(2):157-170.

34. Ozben T. Oxidative stress and apoptosis: impact on cancer therapy. J Pharm Sci. 2007;96(9):2181-2196.

35. Li H, Tian J, Wu A, Wang J, Ge C, Sun Z. Self-assembled silk fibroin nanoparticles loaded with binary drugs in the treatment of breast carcinoma. Int J Nanomedicine. 2016;11:4373.

36. Pelicano H, Carney D, Huang P. ROS stress in cancer cells and therapeutic implications. Drug Resist Updat. 2004;7(2):97-110.

37. Al-Sadoon MK, Abdel-Maksoud MA, Rabah DM, Badr G. Induction of apoptosis and growth arrest in human breast carcinoma cells by a snake (Walterinnesia aegyptia) venom combined with silica nanoparticles: crosstalk between Bcl2 and caspase 3. Cell Physiol Biochem. 2012;30(3):653-665.

38. Badr G, Al-Sadoon MK, Abdel-Maksoud MA, Rabah DM, El-Toni AM. Cellular and molecular mechanisms underlie the anti-tumor activities exerted by Walterinnesia aegyptia venom combined with silica nanoparticles against multiple myeloma cancer cell types. PLoS One 2012;7(12):e51661.

39. Song X, Zhang G, Sun A, et al. Scorpion venom component III inhibits cell proliferation by modulating NF- $\mathrm{\kappa B}$ activation in human leukemia cells. Exp Ther Med. 2012;4(1):146-150.

40. Fretz MM, Høgset A, Koning GA, Jiskoot W, Storm G. Cytosolic delivery of liposomally targeted proteins induced by photochemical internalization. Pharm Res. 2007;24(11):2040-2047.

41. Malam Y, Loizidou M, Seifalian AM. Liposomes and nanoparticles: nanosized vehicles for drug delivery in cancer. Trends Pharmacol Sci. 2009;30(11):592-599.

42. Freag M, Elnaggar Y, Abdelmonsif D, Abdallah OY. Stealth, biocompatible monoolein-based lyotropic liquid crystalline nanoparticles for enhanced aloe-emodin delivery to breast cancer cells: in vitro and in vivo studies. Int J Nanomedicine. 2016;11:4799-4818.

43. Moradhaseli S, Mirakabadi AZ, Sarzaeem A, Dounighi NM, Soheily S, Borumand MR. Preparation and characterization of sodium alginate nanoparticles containing ICD-85 (venom derived peptides). Int J Innova App Stud. 2013;4:534-542.

44. Piao L, Zhang M, Datta J, et al. Lipid-based nanoparticle delivery of Pre-miR-107 inhibits the tumorigenicity of head and neck squamous cell carcinoma. Mol Ther. 2012;20(6):1261-1269.

45. Brigger I, Dubernet C, Couvreur P. Nanoparticles in cancer therapy and diagnosis. Adv Drug Deliv Rev. 2012;64:24-36.

46. Mattheolabakis G, Taoufik E, Haralambous S, Roberts ML, Avgoustakis K. In vivo investigation of tolerance and antitumor activity of cisplatin-loaded PLGA-mPEG nanoparticles. Eur J Pharm Biopharm. 2009;71(2):190-195.

47. Mohammadpour Dounighi N, Eskandari R, Avadi M, Zolfagharian H, Mir Mohammad Sadeghi A, Rezayat M. Preparation and in vitro characterization of chitosan nanoparticles containing Mesobuthus eupeus scorpion venom as an antigen delivery system. $J$ Venom Anim Toxins Incl Trop Dis. 2012;18(1):44-52.

48. Sun $\mathrm{P}$, Huang W, Jin M, et al. Chitosan-based nanoparticles for survivin targeted siRNA delivery in breast tumor therapy and preventing its metastasis. Int J Nanomedicine. 2016;11:4931-4945. 


\section{Publish your work in this journal}

The International Journal of Nanomedicine is an international, peerreviewed journal focusing on the application of nanotechnology in diagnostics, therapeutics, and drug delivery systems throughout the biomedical field. This journal is indexed on PubMed Central, MedLine, CAS, SciSearch $\AA$, Current Contents $\AA /$ Clinical Medicine,
Journal Citation Reports/Science Edition, EMBase, Scopus and the Elsevier Bibliographic databases. The manuscript management system is completely online and includes a very quick and fair peer-review system, which is all easy to use. Visit http://www.dovepress.com/ testimonials.php to read real quotes from published authors.

Submit your manuscript here: http://www.dovepress.com/international-journal-of-nanomedicine-journal 